DOI: $10.32481 / \mathrm{djph} .2021 .07 .010$

\title{
Evolution of the Delaware Epidemiology Response to COVID-19
}

\author{
Erica Smith, MPH, $\mathrm{PhD}^{1}$ and Tabatha N. Offutt-Powell, DrPH, MPH, BS ${ }^{2}$
}

1. Deputy State Epidemiologist, Epidemiology, Health Data, and Informatics Section, Division of Public Health, Delaware Department of Health and Social Services

2. State Epidemiologist; Chief, Epidemiology, Health Data, and Informatics Section, Division of Public Health, Delaware Department of Health and Social Services

\section{ACKNOWLEDGEMENTS}

To the many DPH staff who dedicated hours upon hours upon days and months and now over a year to assist the COVID-19 epidemiology response, words cannot express our most sincere and heartfelt gratitude for what you helped us to achieve by ensuring that public health received laboratory test results, maintaining our surveillance and information systems, investigating cases, making public health recommendations regarding isolation and quarantine, conducting contact tracing, providing data to the My Healthy Community website, and the many more aspects of Delaware's epidemiologic response to the COVID-19 pandemic.

\section{Introduction}

As of June 1, 2021, over 108,000 confirmed and probable cases of coronavirus disease 2019 (COVID-19) and 1,677 deaths have been reported in Delaware since the start of pandemic in March 2020. Over 720,000 persons have been tested in Delaware, including 1.85 million total tests reported. As the pandemic evolved, multiple data systems were used for data management and reporting internally to Division of Public Health leadership and externally to partners and the public. Daily public reporting updates were shared on Delaware's My Healthy Community website since April 2020. This article discusses a history of COVID-19 in Delaware, the changing landscape of data management tools used during the pandemic, and the epidemiology team that has grown and adapted over the past year and a half.

\section{January 2020 - Screening for Patients Under Investigation}

On December 31, 2019, the World Health Organization announced news of patients from Wuhan, China with pneumonia-like symptoms and unknown etiology. ${ }^{1,2}$ As a result, in early January 2020, a Division of Public Health (DPH) team of five infectious disease epidemiologists, one preparedness epidemiologist, the Deputy State Epidemiologist, and State Epidemiologist began preparing for the possibility that the novel coronavirus (then called 2019-nCoV) would arrive in the United States or Delaware. The U.S. Centers for Disease Control and Prevention (CDC) and other governmental partners held weekly and daily all-state calls, press briefings, and other sessions to share information across agencies.

In mid-January, CDC established a patient under investigation (PUI) case definition ${ }^{3}$ to assist health departments in identifying and testing patients. The initial PUI case definition focused solely on symptomatic people with recent travel to Wuhan, or exposure to other PUIs, but was later expanded to include travel to anywhere in mainland China. ${ }^{3}$ In response to calls from providers seeking clinical guidance, DPH developed a Patient Screening Flowchart to help epidemiologists interpret and apply the CDC's January 29, 2020 PUI case definition, which is 
depicted in Figure 1. On January 29, 2020, Delaware announced its first PUI, a hospitalized Kent County resident who later tested negative for $\mathrm{n}-\mathrm{CoV} .{ }^{4}$

Figure 1. Novel Coronavirus (2019 nCOV) Patient Screening Flowchart using January 29, 2020 Patient Under Investigation Case Definition 
Novel Coronavirus (2019 nCoV)

Patient Screening Flowchart

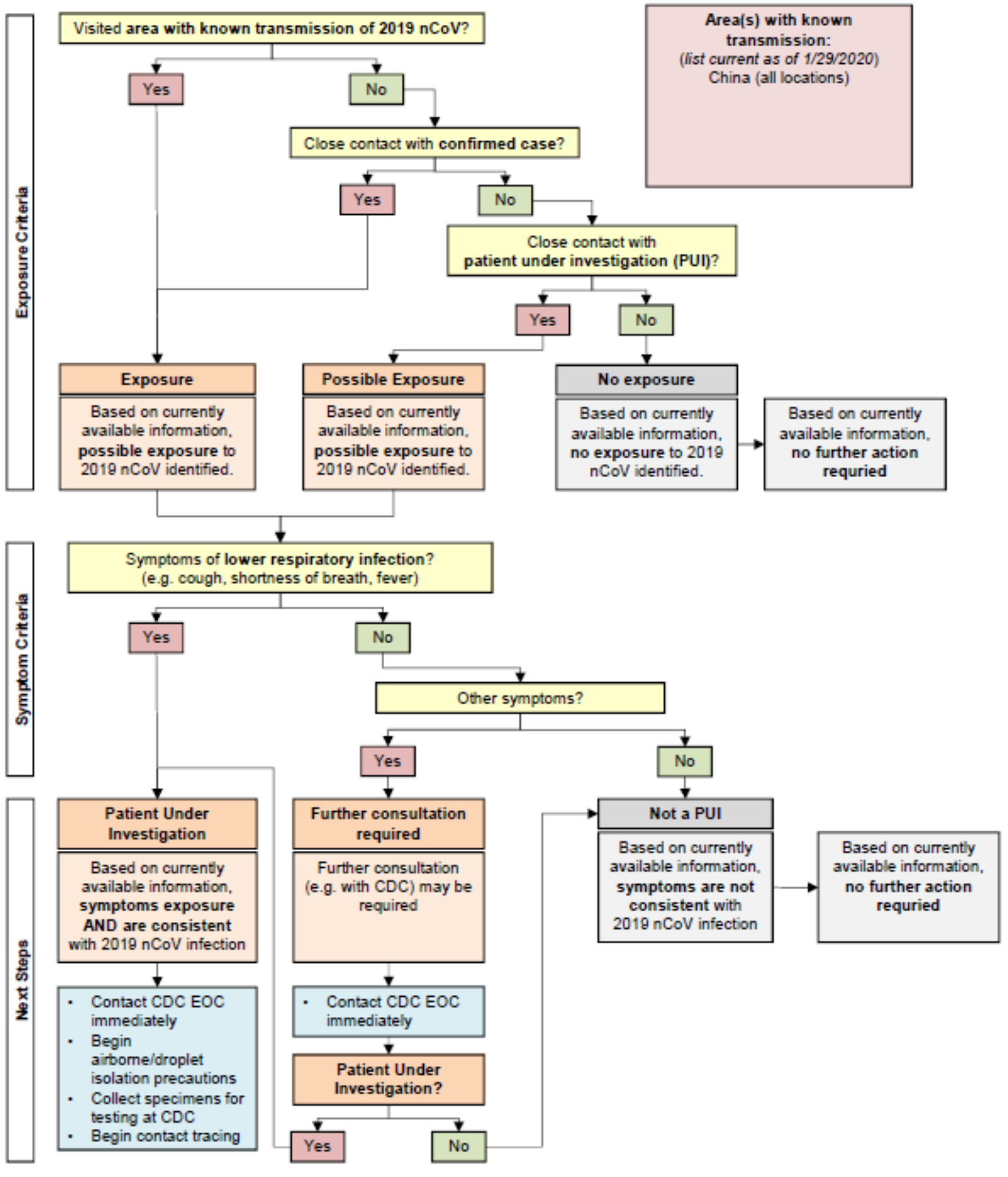

1/29/2020 | Version 1

February 2020 - Traveler Monitoring Program Begins 
On January 31, President Donald Trump announced that travel from China to the United States would be restricted. ${ }^{5}$ Three days later, the CDC, the Transportation Security Administration (TSA), and state and local health departments began a symptom monitoring program for travelers returning from China. ${ }^{5}$ Initially, DPH developed paper questionnaires, illustrated in Figure 2A, for initial interviews and periodic symptom monitoring during the 14-day selfquarantine period, and later used an Epi-Info $7^{\mathrm{TM}}$ database, illustrated in Figure 2b, to manage the traveler monitoring program. In February and March, the traveler monitoring program expanded to include Iran, Japan, South Korea, and Europe, and then any country with a Level 2 or Level 3 travel advisory. ${ }^{6}$ DPH received traveler lists through CDC's secure platform, Epi-X, and contacted recently returned travelers from designated countries to ask them to selfquarantine for 14 days after their return and monitor their symptoms. Between February 5 and April 7, DPH monitored 200 travelers, predominantly those returning from China $(68,34 \%)$ and Europe (36, 18\%).

Figure 2a. Initial Paper Forms Used for Monitoring of Travelers Returning From China 
DOI: $10.32481 /$ djph.2021.07.010

\section{Novel Coronavirus (2019 nCoV) Initial Traveler Risk Assessment}

\section{Interview Information}

\begin{tabular}{|c|l|l|l|l|l|}
\hline Date of Interview & Time & Interviewer Name & 1 $^{\text {st }}$ Attempt & $2^{\text {nd }}$ Attempt & $3^{\text {rd }}$ Attempt \\
\hline$/ /$ & & & & & \\
\hline
\end{tabular}

\section{Traveler Information}

\begin{tabular}{|l|l|c|l|l|}
\hline First Name & Last Name & Date of Birth & Sex & Traveler ID \\
\hline & \multicolumn{1}{|l|}{$/$} & $\square \mathrm{M} \square \mathrm{F}$ & \\
\hline Race/Ethnicity & Language(s) Spoken & $\begin{array}{l}\text { Country of } \\
\text { Permanent Residence }\end{array}$ \\
\hline$\square$ White, non-Hispanic & $\square$ English & $\square$ USA \\
$\square$ Blank, non-Hispanic & $\square$ Mandarin & $\square$ China \\
$\square$ Hispanic/Latino & $\square$ Cantonese & $\square$ Other: \\
$\square$ Asian or Pacific Islander & $\square$ Other: & \\
$\square$ Another/multiple races: & Translator required? $\square \mathrm{Y} \square \mathrm{N}$ & \\
\hline
\end{tabular}

\begin{tabular}{|l|l|l|l|}
\hline US Street Address & City & State & Zip \\
\hline & & & \\
\hline
\end{tabular}

\begin{tabular}{|l|l|l|l|ll|}
\hline Phone & Mobile & $(\quad)$ & - & Home & $(\quad)$ \\
\hline
\end{tabular}

\section{Travel Information}

\begin{tabular}{|c|c|c|c|c|}
\hline $\begin{array}{l}\text { Itinerary } \\
\text { Summary }\end{array}$ & $\begin{array}{l}\text { Mainland China? } \\
\square Y \square N\end{array}$ & $\begin{array}{l}\text { Hubei province/Wuhan City? } \\
\square Y \square N\end{array}$ & & \\
\hline \multirow{5}{*}{$\begin{array}{l}\text { Full } \\
\text { Itinerary } \\
\text { (within } \\
\text { past } \\
14 \text { days) }\end{array}$} & City & Country & Date Arrived & Date Departed \\
\hline & & & $1 /$ & $1 /$ \\
\hline & & & 1 & 1 \\
\hline & & & I & I \\
\hline & & & l & l \\
\hline
\end{tabular}

\begin{tabular}{|l|l|}
\hline Nature of Visit (select all) & Place of residence while traveling (select all) \\
\hline$\square$ Business $\square$ Tourism $\square$ Visit family/friends & $\square$ Hotel $\square$ Hostel or shared room \\
$\square$ Permanent resident of China & $\square$ With local friends/family \\
$\square$ Other: & $\square$ Own residence (if permanent resident of China) \\
& $\square$ Other: \\
\hline
\end{tabular}

\begin{tabular}{|c|l|l|l|l|}
\hline US Arrival Date & Time & Arrival Airport City & State & Airport Name \\
\hline$/ / I$ & & & & \\
\hline Final Arrival Date & Time & Final Airport City (if different) & State & Airport Name \\
\hline$/ /$ & & & & \\
\hline
\end{tabular}

\begin{tabular}{|l|l|l|}
\hline Screened at Airport? & Symptomatic on Screening? & Notes \\
\hline$\square \mathrm{Y} \square \mathrm{N}$ & $\square \mathrm{Y} \square \mathrm{N}$ & \\
\hline
\end{tabular}

\begin{tabular}{|l|l|}
\hline How did you travel from final airport to home? & Notes \\
\hline$\square$ Private vehicle $\square$ Taxi, Car Service, Uber/Lyft & \\
$\square$ Shared van/bus $\square$ Other: & \\
\hline
\end{tabular}

Version 1 | 2/4/2020 | Page 1

Figure 2b. Epi-Info 7 TM Database Used for Management of Traveler Monitoring Program 
DOI: 10.32481/djph.2021.07.010

COVID Traveler/Contact Monitoring- Initial Assessment

Demographic Summary

First Name
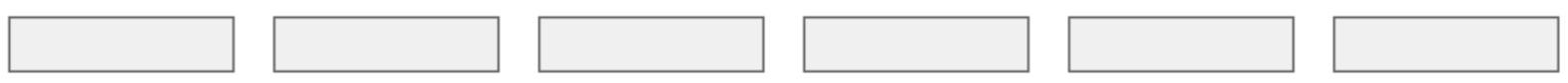

\section{Demographic Information}

First Name

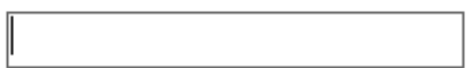

Race/Ethnicity

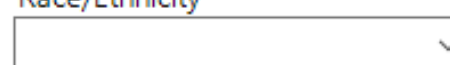

Last Name

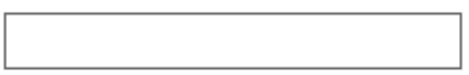

Language(s) Spoken

English

Mandarin

Cantonese

Other Language

Translator required?

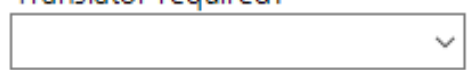

Clty
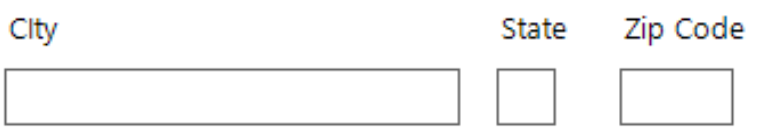

County

Home Phone

Mobile Phone

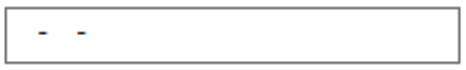

- -

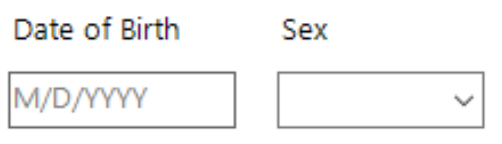

Country of Permanent Residence

$\square$ USA

China

Other Country

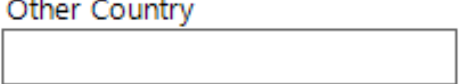

Able to text?

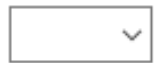

Email

\section{March 2020 - COVID-19 Spreads in the USA; First Cases Identified in Delaware}

In March 2020, COVID-19 began to spread widely in the United States. On March 7, CDC reported 213 cases in 19 states. $^{7}$ Shortly thereafter, on March 11, 2020, Delaware identified its first presumptive positive case of COVID-19 in a Delaware resident. ${ }^{8}$ On March 12, Governor John Carney declared a State of Emergency ${ }^{9}$ and DPH activated its State Health Operations 
DOI: $10.32481 / \mathrm{djph} .2021 .07 .010$

Center (SHOC) at Level 3. All epidemiology staff relocated to the SHOC as other DPH staff were activated to help with COVID-19-related activities. On March 13, all Delaware schools closed $^{10}$; the closure was later extended to the entire school year. ${ }^{11}$

Upon identification of the first cases of COVID-19 in Delaware, DPH developed paper case investigation forms, illustrated in Figure 3. Case investigations were conducted by a fivemember team of epidemiologists that expanded to 12 and included epidemiologists from other DPH programs such as the cancer program, chronic disease program, and HIV/STD programs. Cases were asked about their demographic information, signs and symptoms, underlying health conditions, recent health care visits, employment information, and exposures to other persons with COVID-19. Cases were also asked about any household contacts with whom they may have exposed and any high-risk exposures (e.g., long-term care facilities, group settings, and correctional facilities). Limited information from case investigation questionnaires was entered into a line list managed by a single user in Microsoft Excel, and daily COVID-19 data summaries were sent to internal DPH partners and leadership. The summaries included demographics, hospitalizations, deaths, exposures to other COVID-19 cases, and international/domestic travel. To give a richer picture of the spread, exposures, and risk of COVID-19 in Delaware, deidentified case summaries were shared daily with DPH and intergovernmental leadership.

Figure 3. Initial Paper Forms Used for COVID-19 Case Investigation 
Contact tracing was performed for the first nine COVID-19 cases that were identified in midMarch. Contacts were initially contacted, asked to self-quarantine, and monitored for development of symptoms by a team of six DPH staff who were activated for the SHOC from other programs within the Division. DPH discontinued contact tracing after the first nine cases and reassigned contact tracing staff to other duties within the COVID-19 Epidemiology (COVID Epi) SHOC response.

By March 22, COVID-19 was rapidly spreading throughout the U.S. and 65 cases were identified in Delaware. The same day, Governor Carney announced a stay-at-home order for Delawareans and ordered all non-essential businesses to close. ${ }^{12}$ Four days later, Delaware announced the first COVID-19-related death ${ }^{13}$ and on March 29, out-of-state visitors were asked to quarantine for 14 days upon arrival in Delaware. ${ }^{14}$ In late April, a public mask mandate was issued. $^{15}$

\section{April 2020 - Additional Cases Identified, REDCap Case Investigation Database Deployed}

In April 2020, cases began to spread quickly in Delaware and around the country, with CDC reporting "widespread" COVID activity in 25 states on April 1, 2020. ${ }^{16}$ Figure 4 shows an epidemic curve by week of COVID-19 cases in Delaware from March 11, 2020 to May 15, 2020. The peak of Delaware's first wave occurred during the week of April 19, approximately one month after stay-at-home orders were issued, with 1,531 cases reported.

Figure 4. Confirmed and Probable COVID-19 Cases by Week, Delaware, March 11, 2020 to May 15, 2021.

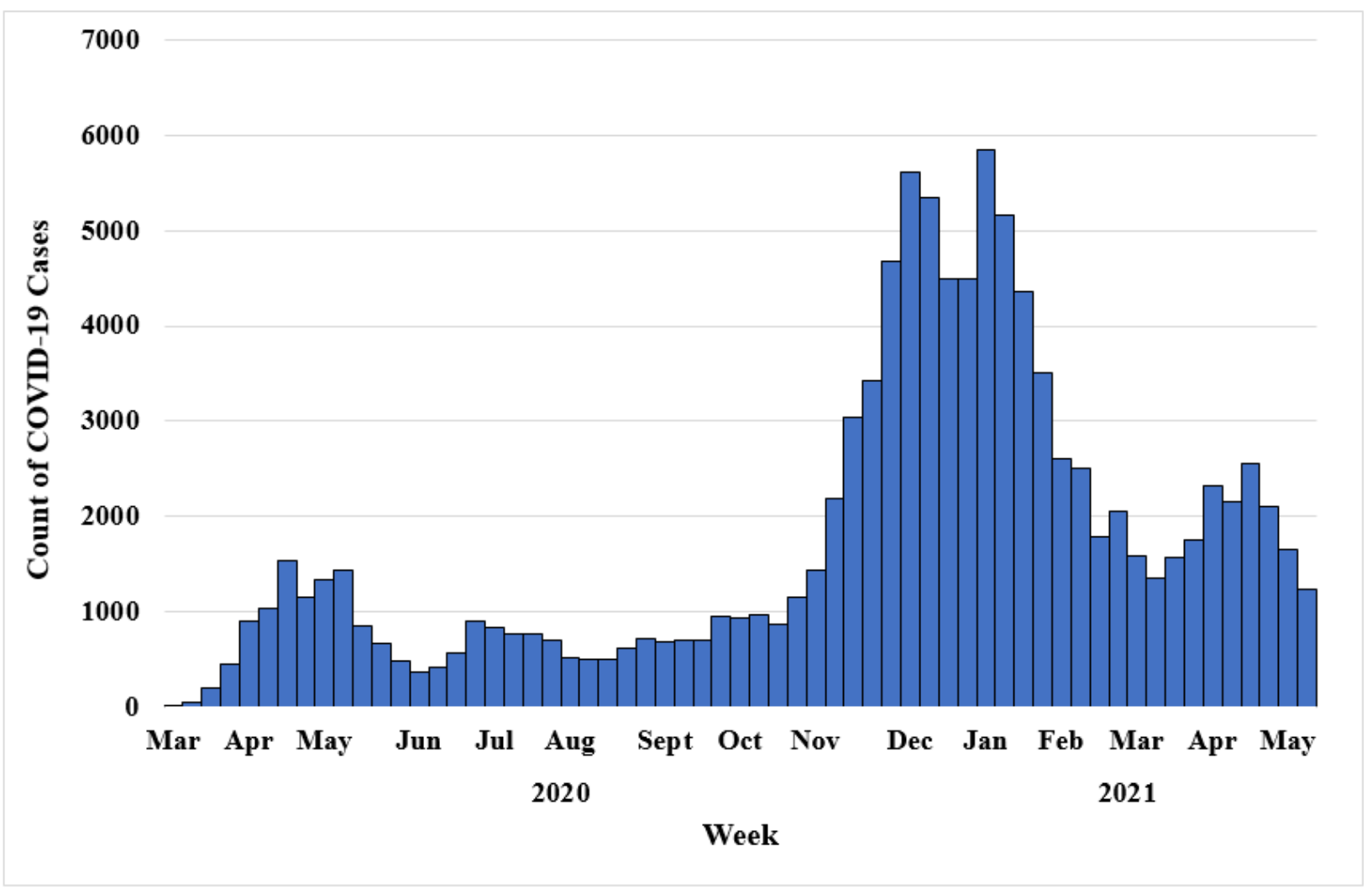


On April 10, 2020, with approximately 1,130 existing cases, DPH replaced its paper forms and Excel line list with a case investigation and symptom monitoring database built in Research Electronic Data Capture (REDCap).${ }^{17}$ Figure 5a shows a screen capture of the REDCap Case Investigation Questionnaire. The COVID Epi Team of 12 cross-cutting epidemiologists conducted case investigation interviews using the new platform, with questions similar to the previously used paper forms. The epidemiologists settled into a rhythm of processing incoming laboratory test results in the Delaware Electronic Reporting and Surveillance System (DERSS) in the morning and conducting case investigation interviews in the afternoon. The team created a daily batch process for new cases to be loaded into the REDCap system (Figure 5b). Each day's reported cases were assigned to an epidemiologist for case interview by the next day. Three call attempts were made to each case before cases were marked as lost to follow-up. DPH stood up a Case Monitoring Team who, using this same REDCap database used for case investigations, routinely called cases during their isolation periods and cleared them from isolation when symptoms resolved.

Figure 5a. REDCap Case Investigation Questionnaire 
Interview Information (if interview completed)

Interview Date

Epi Investigator First and Last Name

Epi Investigator Name

* must provide value

\section{Today M-D-Y}

Date (M-D-Y); Complete only if case is reached- if not reached fill out attempts below instead. Leave blank if case is LTFU

Interviewer first and last name. Complete only if case is reached. Leave blank if attempt is made but case is not reached.

14)

Interviewer first and last name. Complete only if case is reached. Leave blank if attempt is made but case is not reached.

Attempt Information (complete only if case is not reached. If case is reached, complete interview information)

\section{Attempt 1 Date}

Attempt 1 made by (name)

Attempt 2 Date

Attempt 2 made by (name)

Attempt 3 Date

Attempt 3 made by (name)

Demographic Information

Record ID: 682, Name: RECORD LEFT BLANK, RECORD LEFT BLANK

Some data may be imported from DERSS, verify with the case that this information is correct, and fill in any missing information.

\section{Case First Name}

Case Last Name

Date of Birth

Figure 5b. REDCap Case Monitoring Questionnaire
(B)

Date (M-D-Y); complete only if case is not reached. If case is reached, complete interview date instead.

H)

Date (M-D-Y); complete only if case is not reached. If case is reached, complete interview date instead. 
DOI: $10.32481 / \mathrm{djph} .2021 .07 .010$

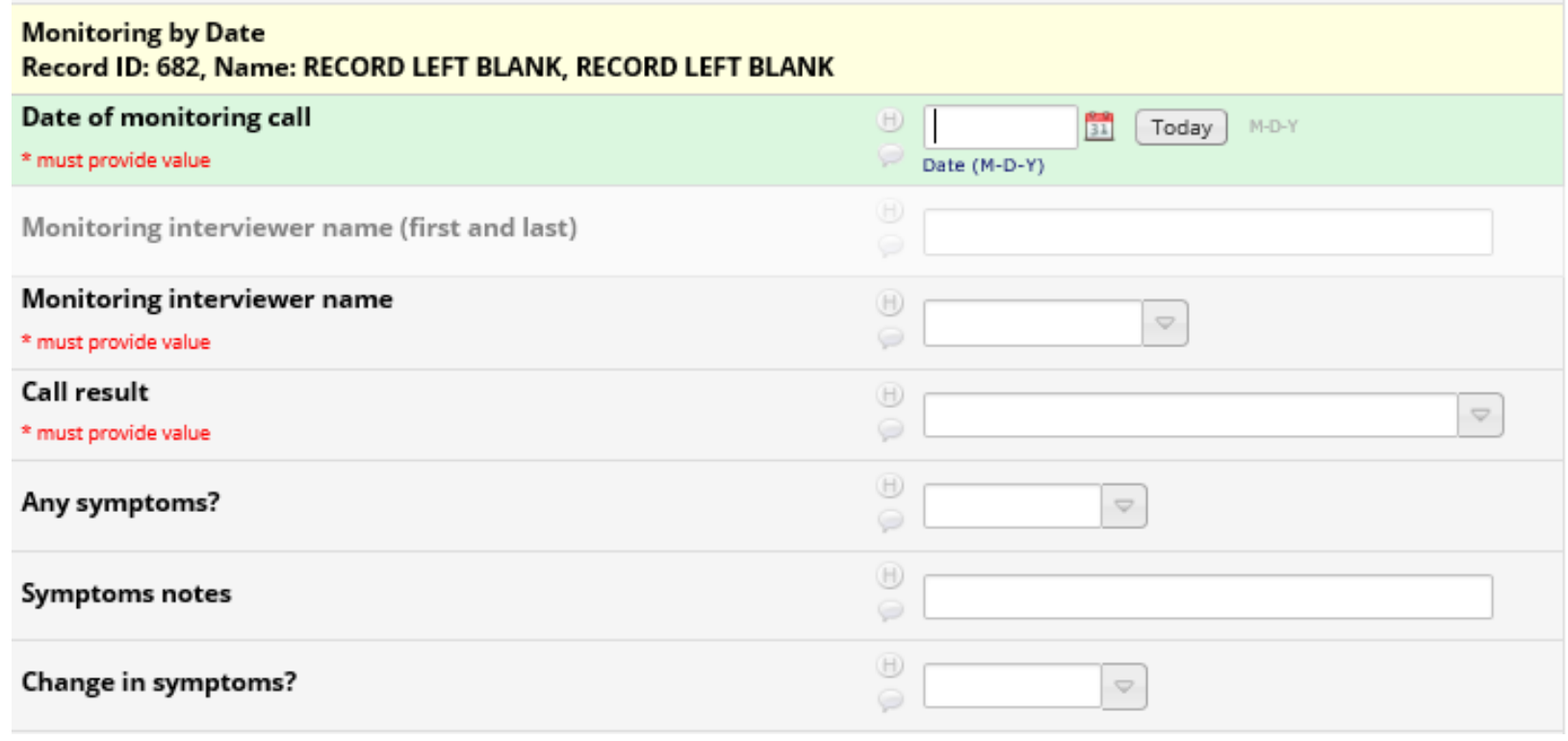

In late April, just after what would later be recognized as the first peak, a large outbreak among poultry plant workers was identified on the Delaware-Maryland-Virginia peninsula. ${ }^{18}$ Among 9,400 workers at six Delaware poultry plants, DPH identified 336 cases and four deaths. ${ }^{18}$ Additional testing and mitigation resources were focused on Sussex County, the epicenter of Delaware's poultry industry, which Governor Carney declared a COVID-19 hotspot on April 28. ${ }^{19}$ Since English was not the primary spoken language for many poultry workers, the COVID Epi team recruited DPH staff who spoke Spanish and Haitian Creole to assist with case interviews; language line translation resources were also used.

\section{May 2020 - Cases Remain Elevated, COVID Epi Team Expands, Contact Tracing Begins}

As cases continued to increase in April and remained elevated in May, additional DPH staff were activated as part of the SHOC COVID Epi response and a revised team structure was implemented. The DERSS Case Creator Team that eventually included 25 members, processed laboratory reports in DERSS every morning and classified cases as "confirmed," "probable," or "not a case" (i.e. negative) using CDC's surveillance case definitions. ${ }^{20}$ The Epi Investigation Team, eventually including 37 members, used REDCap's case investigation database to call cases and conduct initial interviews before transferring cases to the Case Monitoring Team. The Case Monitoring Team, which eventually included 24 members, monitored cases for symptom resolution by calling them periodically until symptoms resolved and individuals were released from isolation. A COVID Epi Data Team including an epidemiologist and two data analysts was established to assist with administration of the data systems used by the team.

On May 12, Governor Carney announced a statewide contact tracing plan "to contain COVID19, limit Delawareans' exposure to the disease, and restart Delaware's economy." ${ }^{21}$ One hundred members of the Delaware National Guard (DNG) were immediately activated to perform contact tracing and began their training. On May 11, cases were asked about any close or household contacts they had who may have been exposed to COVID-19, and a second REDCap database was built exclusively for the DNG to house and manage contact tracing data. Named contacts were extracted from the case investigation REDCap system, imported into the contact tracing 
DOI: $10.32481 / \mathrm{djph} .2021 .07 .010$

REDCap system, and assigned for a DNG call by the next day. A team of epidemiologists and CDC contact tracing experts was deployed to assist with establishing the DNG contact tracing effort, and a summary of contact tracing from May 11 to June 25 was published. ${ }^{22}$

As cases started declining in May, restrictions began to lift in several sectors with masking, social distancing, and capacity restrictions in place. Houses of worship were allowed to reopen, ${ }^{23}$ businesses were allowed to operate by appointment, ${ }^{24}$ and on May 22 preceding Memorial Day, Delaware beaches were reopened with restrictions as a mandatory 14-day quarantine for out-ofstate travelers and a ban on short term rentals remained in effect. ${ }^{25}$

\section{June 2020 - Phase 1 and 2 of Reopening, and Long-Term Contact Tracing}

Beginning on June 1, 2020, Phase 1 of the Delaware COVID-19 reopening plan included an end to the stay-at-home orders and out-of-state quarantine, retail and restaurants reopening at $30 \%$ capacity, and a 250-person cap on outdoor gatherings. Phase 2, which began June 15, expanded retail and restaurant capacity to $60 \%$ and allowed childcare, personal care, and exercise facilities to reopen with restrictions. ${ }^{26}$

Earlier in May, DPH was working on a long-term solution and hired, onboarded, and trained 150 contact tracers with the nonpartisan research institution National Opinion Research Center (NORC) at the University of Chicago. On June 26, DPH launched the new Delaware Contact Tracing System (DCTS). The case investigation and contact tracing REDCap databases were retired, and all the historical data were moved into a new master database using a Salesforce platform (Figure 6). The Epi Investigation Team was trained on the new Salesforce ${ }^{\odot}$ platform. Contact tracers interviewed cases and contacts using questionnaire scripts during live phone calls; individuals who could not be reached were called by the COVID-19 Epi Team or visited by a newly stood up DPH Field Team, which eventually grew to around 45 members and represents DPH's largest Field Team to date.

Figure 6. Delaware Contact Tracing System Case Initial Interview Questionnaire 
DOI: $10.32481 / \mathrm{djph} .2021 .07 .010$

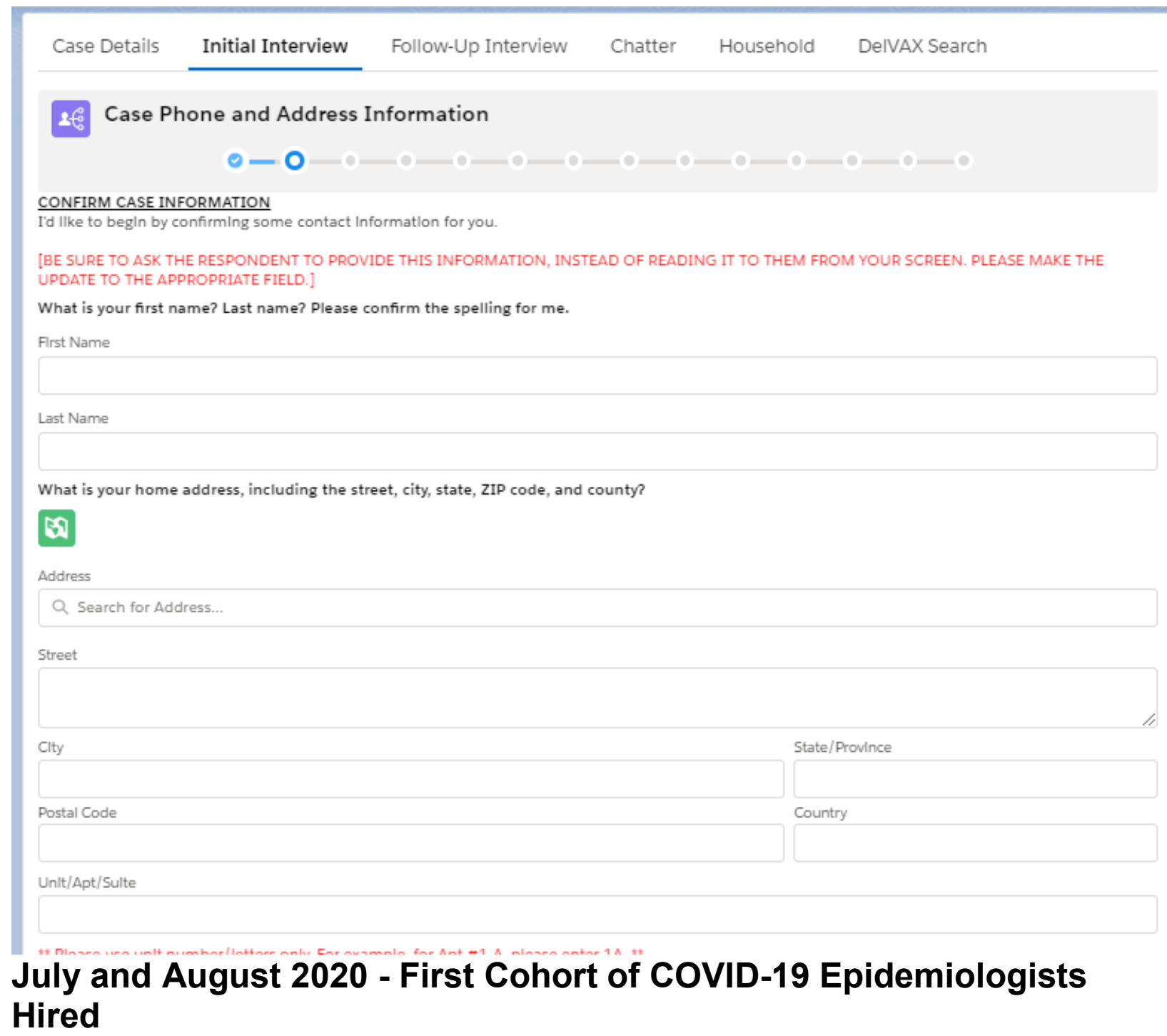

In May, the CDC awarded a $\$ 67$ million Epidemiology Laboratory Capacity (ELC) grant to support COVID-19 activities in Delaware. ${ }^{27}$ From this funding, over a dozen limited term COVID-19 epidemiologist positions were made available. The initial cohort of COVID-19 Epidemiologists (COVID Epis) was hired in July and August. As the dedicated COVID Epi team was trained and onboarded, other SHOC-activated staff on the Epi Investigation and Case Monitoring teams returned to their regular DPH duties.

Initially, the case interview questionnaires in DCTS were focused on identifying exposed contacts and calling contacts to notify them of their exposure and ask them to self-quarantine. Early on, the COVID Epi Team focused on calling cases and contacts that the contact tracers were unable to reach, and the DPH Field Team visited persons the COVID Epi Team was not able to reach, at home. Case counts remained relatively low throughout the summer, with a small second peak in late June/early July (Figure 4). 
During the summer, questions were added to the survey to ask cases where they had been prior to their illness, and where they might have been exposed to COVID-19. The COVID Epi Team began to analyze the data and look for trends among cases to detect possible clusters associated with public venues, private gatherings, and employment.

\section{September and October 2020 - Schools Begin to Reopen, Long-Term Care Cases Increase}

In late summer and early fall 2020, the COVID Epi team began to plan for school reopening working with school nurses to coordinate contact tracing activities. During school year 20202021, schools were allowed to reopen for hybrid learning ${ }^{28}$; families chose whether students would attend school in-person or remotely if the school district allowed an in-person option. DPH and the Department of Education issued reopening guidance for schools ${ }^{29}$ and a dedicated COVID Epi School Team of seven epidemiologists was established to answer calls from school nurses about cases or exposures in their schools.

When cases and outbreaks in long-term care facilities began to increase in September, DPH began releasing case totals by facility among facilities experiencing significant outbreaks of COVID-19. ${ }^{30}$ A dedicated COVID Epi Long-term Care Team of four epidemiologists was created to manage inquiries from long-term care facilities, using a resource email account where facilities could submit inquiries, daily line lists, and other information.

\section{November and December 2020 - Holiday Surge and the Third Wave}

COVID-19 cases began to steadily increase as temperatures dropped in late fall and winter 2020, culminating with two peaks during the weeks of December 6, 2020 and January 3, 2021. Each peak occurred about 10 days after the Thanksgiving and Christmas holidays. On November 17, Governor Carney announced additional COVID-19 restrictions, including a 10-person limit on private gatherings and a $30 \%$ restriction on indoor restaurant capacity. ${ }^{31}$

As the surge began in November, priorities for the COVID-19 Epi Team shifted from interviewing individual cases and contacts to classifying cases daily in DERSS and detecting and responding to cases and clusters in high-risk settings. As of early December, the DERSS Case Creator Team and all but two SHOC-activated staff had returned to their regular jobs within DPH, and the COVID Epi Team included 20 epidemiologists and five additional support staff. There were now five teams: the existing Data Team, School Team, and Long-Term Care Team, plus two new teams, the Cluster Team and the Queues Team. Funding for additional COVID-19 Epi staff and team leads was identified to continue to respond to the growing need for epi support, particularly for school-related calls and clusters detected following holiday gatherings.

To address the surge, on December 3, additional public COVID-19 restrictions were announced. They included a stay-at-home advisory and universal indoor mask order; a reduction in capacity in large retail stores to 20\%; and a "pause" on hybrid K-12 school learning from December 14 to January $11,2021 .^{32-34}$

As COVID-19 vaccines were approved in December 2020, DPH activated its vaccination plan and strongly recommended eligible Delawareans to receive the vaccine as soon as possible.

Health care personnel, emergency medical services personnel, and the residents and staff of long-term care facilities were the first to become eligible in Phase 1A. A critical care nurse was 
DOI: $10.32481 /$ djph.2021.07.010

the first Delawarean to receive the vaccine on December $15 .{ }^{35}$ Vaccination of long-term care residents and staff began on December $17 .{ }^{36}$

\section{January and February 2021 - Solidifying the COVID Epi Team Structure}

COVID-19 cases remained high through January and February 2021, and the COVID Epi Team continued to detect and respond to clusters and inquiries from schools and nursing homes. During and after the K-12 school hybrid learning "pause," while schools returned to hybrid learning and school-related calls dropped significantly, the COVID-19 Epi Team regrouped and reviewed its resources, capacity, and structure, resulting in teams streamlining activities. The School Team moved from managing school-related calls in a single-user Excel spreadsheet to a School Triage REDCap database. This new database allows school nurses to submit inquiries to the COVID Epi Team using a web form. Those inquiries were then immediately assigned to an epidemiologist to follow-up. Although the volume of inquiries remained high due to the ongoing surge in cases, critical information was collected from school nurses up front, reducing the need for back-and-forth phone calls between the COVID Epi Team and school nurses. A team of 12 DNG members were onboarded to re-establish a DERSS CaseCreation team, allowing COVID Epi staff time to respond to high-priority cases and clusters in high-risk settings.

On January 19, Delaware transitioned to Phase 1B of its vaccination plan, ${ }^{37}$ focusing on persons age 65 and older, frontline essential workers, and Phase 1A-eligible persons who had not yet been vaccinated. An electronic system was launched for eligible individuals to request a vaccine appointment, and it received more than 56,000 requests on its first day. ${ }^{38}$ Although not detailed here within, the state's vaccination response efforts were a coordinated government effort that served as a primary prevention avenue for the state to drastically impact the spread of the virus.

The Delaware Public Health Laboratory (DPHL) began sequencing its COVID-19 specimens, and on January 29 identified the first three cases of COVID-19 variant SARS-CoV-2 B.1.1.7 (Alpha), which was first identified in the United Kingdom. ${ }^{39}$ With sequencing of specimens on the rise, the Cluster Team began tracking all variant cases in Delaware. On March 5, DPH announced the first case of another COVID-19 variant, SARS-CoV-2 B.1.351 (Beta), first identified in South Africa. ${ }^{40}$

As distribution of vaccines expanded in long-term care facilities, nursing home cases began to fall, and DPH announced on February 12 that it would report COVID-19 cases and deaths in long-term care facilities weekly instead of daily. ${ }^{41}$ By late March, DPH released guidance for inperson visitation in nursing homes. ${ }^{42}$

\section{March, April, May 2021 - Vaccine Rollout, Breakthrough, and Variant Cases}

In March, the COVID-19 Queues Team began tracking cases who tested positive for COVID-19 after being fully vaccinated. During case interviews, cases were asked about COVID-19 vaccination. If more than 14 days had passed since their last dose, they were classified as "breakthrough" cases. Breakthrough cases, hospitalizations, and deaths were reported to CDC until May 1, when reporting was limited to only hospitalizations and deaths among breakthrough cases. $^{43}$ As of May 27, DPH identified 330 cases of COVID-19 among fully-vaccinated 
individuals in Delaware, out of more than 381,498 Delaware residents who are fully vaccinated $(0.09 \%){ }^{44}$

On March 17, COVID-19 vaccination opened to all Delawareans over 50 and anyone 16 and older with high- and moderate-risk health conditions. ${ }^{45}$ At that time, $20 \%$ of Delaware's population had received at least one dose of a COVID-19 vaccine, and case counts began to decline to counts only slightly higher than those before the winter surge as illustrated in Figure 4. Just a few weeks later on April 6, COVID-19 vaccination opened to all Delawareans 16 and older. $^{46}$

In April 2021, COVID-19 cases once again began to rise, with a small peak the week of April 4. Variants of concern continued to be identified, with 64 cases of B.1.1.7 reported by April 9. ${ }^{47}$ The B.1.1.7 variant was the dominant variant in the United States on April 10, accounting for $59.5 \%$ of all sequenced COVID-19 specimens, according to the CDC. ${ }^{48}$ By May 14, DPHL identified 568 cases of the B.1.1.7 variant out of 2,215 specimens sequenced. ${ }^{49}$

May 14 marked the first week where fewer than 1,000 cases were identified since October 2020. DPH retired its COVID-19 vaccination "wait list" (appointment request system) on May 6, reflecting increases in vaccine supply and uptake around the state. ${ }^{50}$ As of May 14, over 830,000 doses of COVID-19 vaccines were administered, $56 \%$ of the eligible population had received at least one dose, and more than $44 \%$ were fully vaccinated. ${ }^{49}$

\section{May 2021 and Beyond - the Future of the Delaware COVID Epi Team}

Sixteen months into the pandemic, as vaccine doses administered increase and cases counts continue to decline, the COVID-19 Epi Team is looking to the future and how best to adapt to a rapidly changing pandemic in Delaware. DPH brought a COVID Epi Bureau Chief on board in late March of 2021, and a senior Epidemiologist in late May. The Senior Epidemiologist will assume many day-to-day COVID-19 responsibilities from the State Epidemiologist and Deputy State Epidemiologist, who will return to supporting other epidemiology and program staff throughout the Division.

The COVID-19 Epi Team is committed to continuous quality improvement and constantly evaluates the epidemiology needs of the COVID-19 response in Delaware. With anticipated testing to occur in schools during the summer and fall, the School Team is planning to address any potential increases in cases among school students and staff, and inquiries from school nurses, once the 2021-2022 school year begins. The Cluster Team continues to track variant cases to document the changing picture of variants of concern and interest in Delaware. The Data Team continues to identify opportunities to streamline daily and weekly reports, transitioning more fully into "big data" analysis strategies as COVID-19 cumulative case counts and testing continue to increase over time. The Long-Term Care team continues to respond to inquiries from facilities regarding both cases, clusters, and deaths. The Queues team continues to improve the DCTS and track breakthrough cases, monitoring trends as vaccination numbers increase.

From humble beginnings of a small team and paper forms, the Delaware COVID Epi Team has grown and adapted to a rapidly changing pandemic and is ready to take on the new challenges in what lies ahead. 
DOI: $10.32481 / \mathrm{djph} .2021 .07 .010$

Corresponding author: Erica Smith, MPH, PhD is the Deputy State Epidemiologist in the Division of Public Health, Delaware Department of Health and Social Services.

erica.smith@delaware.gov

\section{References}

1. Allam Z. (2020). The first 50 days of COVID-19: A detailed chronological timeline and extensive review of literature documenting the pandemic. Surveying the Covid-19 Pandemic and its Implications, 1-7. https://doi.org/10.1016/B978-0-12-824313-8.00001

2. World Health Organization. (2020, December 28). Listings of WHO's response to COVID19. World Health Organization News. https://www.who.int/news/item/29-06-2020covidtimeline

3. Centers for Disease Control and Prevention. (2020, January 17). Interim guidance for healthcare professionals. 2019 Coronavirus.

https://web.archive.org/web/20200130185924/https://www.cdc.gov/coronavirus/2019$\mathrm{nCoV} / \mathrm{hcp} / \mathrm{clinical}$-criteria.html

4. Delaware Department of Health and Social Services. (2020, January 30). News. Information on 2019 Novel Coronavirus from Division of Public Health. https://news.delaware.gov/2020/01/30/information-on-2019-novel-coronavirus-fromdivision-of-public-health/

5. U.S. Department of Homeland Security. (2020, February 2). DHSS issues supplemental instructions for inbound flight with individual who have been in China. News Archive. https://www.dhs.gov/news/2020/02/02/dhs-issues-supplemental-instructions-inboundflights-individuals-who-have-been-china

6. National Public Radio. (2020, February 29). Map: Which countries have CDC travel advisories because of coronavirus. The Coronavirus Crisis. https://www.npr.org/sections/goatsandsoda/2020/02/29/810440382/map-which-countrieshave-cdc-travel-advisories-because-of-coronavirus

7. Centers for Disease Prevention and Control. (2020, March 8). Updated guidance on evaluating and testing persons for coronavirus disease 2019 (COVID-19). CDC Health Alert Network. https://emergency.cdc.gov/han/2020/HAN00429.asp

8. Delaware Department of Health and Social Services. (2020, March 11). Public Health announces first presumptive positive case of coronavirus in Delaware resident. News. https://news.delaware.gov/2020/03/11/public-health-announces-first-presumptive-positivecase-of-coronavirus-in-delaware-resident/

9. Carney, G. J. (2020, March 12). Declaration of a State of Emergency for the state of Delaware due to a public health threat. Office of the Governor. https://governor.delaware.gov/health-soe/state-of-emergency

10. Carney, G. J. (2020, May 23). Governor Carney closes Delaware schools through May 15. Office of the Governor. https://news.delaware.gov/2020/03/23/governor-carney-closesdelaware-schools-through-may-15/ 
DOI: $10.32481 / \mathrm{djph} .2021 .07 .010$

11. Carney, G. J. (2020, April 24). Delaware schools closed through academic year. Office of the Governor. https://news.delaware.gov/2020/04/24/delaware-schools-closed-throughacademic-year/

12. Carney, G. J. (2020, March 22). Governor Carney issues stay-at-home order for Delawareans. Office of the Governor. https://news.delaware.gov/2020/03/22/governorcarney-issues-stay-at-home-order-for-delawareans/

13. Delaware Department of Health and Social Services. (2020, March 26). Public Health announces first coronavirus-related death of Delaware resident. News.

https://news.delaware.gov/2020/03/26/public-health-announces-first-coronavirus-relateddeath-of-delaware-resident/

14. Carney, G. J. (2020, March 29). Governor Carney order out-of-state travelers to immediately self-quarantine for 14 days. Office of the Governor.

https://news.delaware.gov/2020/03/29/governor-carney-orders-out-of-state-travelers-toimmediately-self-quarantine-for-14-days/

15. Carney, G. J. (2020, April 25). Governor Carney requires Delawareans to wear face coverings in public settings. Office of the Governor.

https://news.delaware.gov/2020/04/25/governor-carney-requires-delawareans-to-wear-facecoverings-in-public-settings/

16. Schuchat, A., \& the CDC COVID-19 Response Team. (2020, May 8). Public health response to the initiation and spread of pandemic COVID-19 in the United States, February 24-April 21, 2020. MMWR. Morbidity and Mortality Weekly Report, 69(18), 551-556. https://doi.org/10.15585/mmwr.mm6918e2 PubMed

17. Vanderbilt. (n.d.). Research Electronic Data Capture. REDCap. https://www.projectredcap.org/

18. Dyal, J. W., Grant, M. P., Broadwater, K., Bjork, A., Waltenburg, M. A., Gibbins, J. D., .. . Honein, M. A. (2020, May 8). COVID-19 Among Workers in Meat and Poultry Processing Facilities - 19 States, April 2020. MMWR. Morbidity and Mortality Weekly Report, 69(18), 557-561. https://doi.org/10.15585/mmwr.mm6918e3 PubMed

19. Carney, G. J. (2020, April 28). Governor Carney declares COVID-19 hot spot in Sussex County, announces expansion of community testing sites. Office of the Governor. https://news.delaware.gov/2020/04/28/governor-carney-declares-covid-19-hot-spot-insussex-county-announces-expansion-of-community-testing-sites/

20. Centers for Disease Control and Prevention. (n.d.). Coronavirus Disease 2019 (COVID-19) 2020 interim case definition, approved August 5, 2020. National Notifiable Disease Surveillance System. ((https://wwwn.cdc.gov/nndss/conditions/coronavirus-disease-2019covid-19/case-definition/2020/08/05/)

21. Carney, G. J. (2020, May 12). Governor Carney announces statewide contact tracing plan for COVID-19. Office of the Governor. (https://news.delaware.gov/2020/05/12/governorcarney-announces-statewide-contact-tracing-plan-for-covid-19/)

22. Kanu, F. A., Smith, E. E., Offutt-Powell, T., Hong, R., Dinh, T. H., \& Pevzner, E., \& the Delaware Case Investigation and Contact Tracing Teams. (2020, November 13). Declines in SARS-CoV-2 transmission, hospitalizations, and mortality after implementation of 
DOI: $10.32481 / \mathrm{djph} .2021 .07 .010$

mitigation measures - Delaware, March-June 2020. MMWR. Morbidity and Mortality Weekly Report, 69(45), 1691-1694. https://doi.org/10.15585/mmwr.mm6945e1 PubMed

23. Carney, G. J. (2020, May 18). Governor Carney issues guidance for churches, houses of worship. Office of the Governor. https://news.delaware.gov/2020/05/18/governor-carneyissues-guidance-for-churches-houses-of-worship/

24. Carney, G. J. (2020, May 19). Governor Carney announces additional interim steps for retail, restaurant businesses to expand operations. Office of the Governor.

https://news.delaware.gov/2020/05/19/governor-carney-announces-additional-interim-stepsfor-retail-restaurant-businesses-to-expand-operations/

25. Carney, G. J. (2020, May 14). Governor Carney reopening of beaches to Delawareans. Office of the Governor. https://news.delaware.gov/2020/05/14/governor-carney-announcesreopening-of-beaches-to-delawareans/

26. Carney, G. J. (2020, June 2). Governor Carney announces Phase 2 of Delaware's economic reopening to begin on June 15 . Office of the Governor.

https://news.delaware.gov/2020/06/02/governor-carney-announces-phase-2-of-delawareseconomic-reopening-to-begin-on-june-15/

27. Delaware Department of Health and Social Services. (2020, March 21). Division of Public Health awarded $\$ 67$ million grant. News. https://news.delaware.gov/2020/05/21/division-ofpublic-health-awarded-67-million-grant/

28. Carney, G. J. (2020, August 4). Governor Carney announces Delaware schools may reopen in hybrid scenario. Office of the Governor. https://news.delaware.gov/2020/08/04/governorcarney-announces-delaware-schools-may-open-in-hybrid-scenario/

29. Delaware Department of Education. (n.d.). Guidance, resources in school year 2020 - 2021. COVID-19. https://www.doe.k12.de.us/Page/4242)

30. Delaware Department of Health and Social Services. (2020, September 25). Delaware surpasses 20,000 positive cases of COVID-19; new daily cases remain elevated. News. https://news.delaware.gov/2020/09/25/delaware-surpasses-20000-positive-case-of-covid-19new-daily-cases-remain-elevated/

31. Carney, G. J. (2020, November 17). Governor Carney announces additional COVID-19 restrictions. Office of the Governor. https://news.delaware.gov/2020/11/17/governor-carneyannounces-additional-covid-19-restrictions/

32. Carney, G. J. (2020, December 3). Governor Carney announces stay-at-home advisory, universal indoor mask order. Office of the Governor.https://news.delaware.gov/2020/12/03/governor-carney-announces-stay-at-homeadvisory-universal-indoor-mask-order/

33. Carney, G. J. (2020, December 10). Governor Carney announces additional COVID-19 restrictions to confront winter surge. Office of the Governor.https://news.delaware.gov/2020/12/10/governor-carney-announces-additionalcovid-19-restrictions-to-confront-winter-surge/ 
DOI: $10.32481 /$ djph.2021.07.010

34. Carney, G. J. (2020, December 3). Message from Governor Carney on COVID-19. Office of the Governor.https://news.delaware.gov/2020/12/03/message-from-governor-carney-oncovid-19/)

35. Carney, G. J. (2020, December 15). Governor Carney, DPH, Bayhealth announce first Delawarean has received the COVID-19 vaccine. Office of the Governor.

https://news.delaware.gov/2020/12/15/governor-carney-dph-bayhealth-announce-firstdelawarean-has-received-the-covid-19-vaccine/

36. Carney, G. J. (2020, December 17). Delaware begins COVID-19 vaccinations in long-term care facilities. Office of the Governor. https://news.delaware.gov/2020/12/17/delawarebegins-covid-19-vaccinations-in-long-term-care-facilities/

37. Carney, G. J. (2021, January 19). Governor Carney, DPH announce transition to vaccinate Phase 1B. Office of the Governor. https://news.delaware.gov/2021/01/19/governor-carneydph-announce-transition-to-vaccinate-phase-1b/)

38. Delaware.gov. (2021, January 20). DPH system for vaccination requests starts with more than 56K signups in first day. Delaware News. https://news.delaware.gov/2021/01/20/dphsystem-for-vaccination-requests-starts-with-more-than-56k-signups-in-first-day/

39. Delaware.gov. (2021, January 29). Delaware Division of Public Health confirms first COVID-19 cases with the UK variant. Delaware News.

https://news.delaware.gov/2021/01/29/delaware-division-of-public-health-confirms-firstcovid-19-cases-with-the-uk-variant/

40. Delaware Department of Health and Social Services. (2021, March 5). New positive cases begin to level off; DPH confirms first COVID-19 case with South African variant. News. https://news.delaware.gov/2021/03/05/new-positive-cases-begin-to-level-off-dph-confirmsfirst-covid-19-case-with-south-african-variant/

41. Delaware Department of Health and Social Services. (2021, February 13). Weekly COVID19 update - Feb. 12, 2021: new positive cases flatten as hospitalizations trend downward. News. https://news.delaware.gov/2021/02/13/weekly-covid-19-update-feb-12-2021-newpositive-cases-flatten-as-hospitalizations-trend-downward/

42. Delaware Department of Health and Social Services. (2021, March 26). DHSS updates guidance for visitation at Delaware's long-term care facilities. News.

https://news.delaware.gov/2021/03/26/dhss-updates-guidance-for-visitation-at-delawareslong-term-care-facilities/

43. Centers for Disease Control and Prevention. (2021, June 11). COVID-19 vaccine breakthrough case investigation and reporting. COVID-19 vaccination. Health Departments. https://www.cdc.gov/vaccines/covid-19/health-departments/past-breakthrough-data.html

44. Delaware Department of Health and Social Services. (2021, June 1). Weekly COVID-19 update - May 28, 2021: Delaware sees lowest number of cases since August. News. https://dhss.delaware.gov/dhss/pressreleases/2021/weeklyupdate_060121.html

45. Carney, G. J. (2021, March 16). Governor Carney, DPH announces updates to COVID-19 vaccination program. Office of the Governor. https://news.delaware.gov/2021/03/16/governor-carney-announces-updates-to-covid-19vaccination-program-2/ 
DOI: $10.32481 / \mathrm{djph} .2021 .07 .010$

46. Carney, G. J. (2021, March 30). COVID-19 vaccination program will open to Delawareans 16+ on April 6. Office of the Governor. https://news.delaware.gov/2021/03/30/covid-19vaccination-program-will-open-to-delawareans-16-on-april-6/

47. Delaware Department of Health and Social Services. (2021, April 9). Weekly COVID-19 update - April 9, 2021: average daily cases decrease; current hospitalizations continue upward trend. News. https://news.delaware.gov/2021/04/09/weekly-covid-19-update-april9-2021-average-daily-cases-decrease-current-hospitalizations-continue-upward-trend/

48. Centers for Disease Control and Prevention. (n.d.). Variant proportions. COVID Tracker. https://covid.cdc.gov/covid-data-tracker/\#variant-proportions

49. Delaware Department of Health and Social Services. (2021, May 14). Weekly COVID-19 update - May 14, 2021: daily cases, hospitalizations continue downward trend. News. https://news.delaware.gov/2021/05/14/weekly-covid-19-update-may-14-2021-daily-caseshospitalizations-continue-downward-trend/

50. Delaware Department of Health and Social Services. (2021, May 6). Delaware COVID-19 vaccination "waiting list" ends. News. https://news.delaware.gov/2021/05/06/delawarecovid-19-vaccination-waiting-list-ends/

Copyright (c) 2021 Delaware Academy of Medicine / Delaware Public Health Association.

This is an Open Access article distributed under the terms of the Creative Commons Attribution Non-Commercial License (https://creativecommons.org/licenses/by-nc-nd/4.0/) which permits unrestricted non-commercial use, distribution, and reproduction in any medium, provided the original work is properly cited. 